\title{
INGESTÃO DE CORPO ESTRANHO DE CHUMBO POR CÃO DA RAÇA Daschund - RELATO DE CASO
}

Renata Panichi da Veiga de Lucca ${ }^{1}$

LUCCA, R. P. da V. de. Ingestão de corpo estranho de chumbo por cão da raça Daschund - relato de caso. Arq. Ciênc. Vet. Zool. UNIPAR, Umuarama, v. 20, n. 2, p. 79-82, abr./jun. 2017.

RESUMO: O presente trabalho relata a ingestão de corpo estranho de chumbo por um cão da raça Daschund, fêmea, atendido em uma clínica particular no município de Pitanga-PR visualizado pelo proprietário há aproximadamente 20 dias. A paciente apresentava vomito há 48 horas, mas apresentava-se hidratada e demais parâmetros dentro da normalidade. O diagnóstico foi confirmado com radiografia simples e o protocolo terapêutico instituído foi o cirúrgico. Apesar do tempo de exposição ao objeto púmblico, a paciente não apresentava alterações clinicas de intoxicação pelo metal. Após 10 dias da gastrotomia, a paciente recebeu alta e permaneceu sem sinais de intoxicação pelo chumbo até o momento.

PALAVRAS-CHAVE: Cão. Gastrotomia. Intoxicação.

\section{INGESTION OF LEAD OBJECT BY A Daschund DOG - CASE REPORT}

\begin{abstract}
This study reports the ingestion of a lead object by a female Daschund dog attended in a private clinic in the city of Pitanga - PR witnessed by the owner 20 days before. The patient presented vomit for 48 hours but it was hydrated, with other parameters within normality. The diagnosis was confirmed with an X-ray and surgery was the therapeutic treatment of choice. In spite of the time of exposure to the lead object, the patient did not present clinical signs of intoxication by the metal. Ten days after the gastrostomy, the patient was discharged and did not present further signs of intoxication.
\end{abstract}

KEYWORDS: Dog. Gastrostomy. Intoxication.

\section{INGESTIÓN DE CUERPO EXTRAÑO DE PLOMO POR PERRO DE LA RAZA Daschund - RELATO DE CASO}

RESUMEN: El presente trabajo relata la ingestión de un cuerpo extraño de plomo por un perro de la raza Daschund, hembra, atendido en una clínica particular en el municipio de Pitanga-PR visualizado por el propietario hacía aproximadamente 20 días. La paciente presentaba vomito hacía 48 horas, pero se presentaba hidratada y demás parámetros dentro de la normalidad. El diagnóstico se ha confirmado con radiografía simple y el protocolo terapéutico instituido fue el quirúrgico. A pesar del tiempo de exposición al objeto plúmbeo, la paciente no presentaba alteraciones clínicas de intoxicación por el metal. Después de 10 días de la gastrostomía, la paciente recibió alta y permaneció sin signos de intoxicación por el plomo hasta el momento. PALABRAS CLAVE: Perro. Gastrostomía. Intoxicación.

\section{Introdução}

Um corpo estranho gástrico é qualquer coisa ingerida por um animal que não pode ser digerida (ou seja, pedra, plástico) ou é digerida lentamente (ossos). Cães são ingeridores indiscriminados e frequentemente ingerem pedras, brinquedos de plástico, sacos de cozinha e outros objetos (FOSSUM, 2005). Segundo o mesmo autor, os gatos ingerem mais comumente materiais lineares (por exemplo, fios de costura presos a agulhas, fios de tecido).

Nem todos os corpos estranhos causam sinais clínicos, podendo permanecer no estômago do animal sem qualquer sintoma por longos períodos (ETTINGER; FELDMAN, 1997).

Muitos deles permanecem assintomáticos, causando sinais clínicos somente quando se obstrui o piloro. A maioria dos corpos estranhos causa pequenos danos na mucosa gástrica, embora possam ocorrer erosões, ulcerações e mesmo perfurações (STURGESS, 2001).

Corpos estranhos rombos e pequenos podem atravessar o sistema digestório sem causar danos, no entanto, a maior parte deles deve ser removida quando é diagnosti- cada, por causa do risco de obstrução e perfuração (FOSSUM, 2005). Ocasionalmente, os corpos estranhos gástricos tornam-se potencialmente perigosos devido ao seu conteúdo (STURGESS, 2001).

As radiografias contrastadas e a endoscopia são os métodos mais confiáveis de se fazer o diagnóstico (WILLARD, 2010).

Corpos estranhos radiopacos podem ser diagnosticados com radiografias simples, mas muitos corpos estranhos são radioluscentes, podendo ser necessários estudos contrastados para delinear corpos estranhos radioluscentes (FOSSUM, 2005).

Anzóis, baterias e objetos de chumbo devem ser removidos para evitar intoxicação (MARCINTIRE, 2007). Tanto em animais de companhia quanto em animais de produção, a intoxicação por chumbo geralmente é manifestada pela sua forma aguda, sendo difícil observar sua forma crônica (HUEZA, 2008).

Após absorvido, o chumbo se distribui pelos tecidos orgânicos sendo os eritrócitos as células escolhidas para a deposição desse metal, ligando-se principalmente à hemoglobina. O segundo principal tecido de deposição desse metal 
pesado é o ósseo, pois compete com o cálcio, já no sistema nervoso central, o chumbo interfere na transmissão nervosa dependente de acetilcolina (HUEZA, 2008).

Distúrbios renais, hipertensão arterial, carcinogenicidade também são relatados na intoxicação por esse metal, além de efeitos reprodutivos com possível aumento de abortos, malformações, natimortos e redução na contagem de espermatozóides (RUPPENTHAL, 2013)

Em animais de companhia, a sintomatologia nervosa é caracterizada por alterações comportamentais, apatia, ataxia, nistagmo, opistótono, convulsões, e em alguns casos, pode ocorrer cegueira. As alterações produzidas no trato gastrintestinal são vômito, anorexia, dor abdominal e diarréia. Em gatos, ainda é relatada a ocorrência de poliúria/polidipsia, megaesôfago e disfagia (HUEZA, 2008). O prognóstico é normalmente bom a menos que o animal esteja debilitado ou que haja peritonite secundária á perfuração gástrica (WILLARD, 2010).

Sendo assim, o objetivo do presente trabalho foi relatar a ingestão de corpo estranho de chumbo em uma cadela da raça Daschund de dois anos sem sinais de intoxicação sistêmica, apesar do longo período de exposiçãogástrica ao metal.

\section{Relato de Caso}

Foi atendida em dezembro de 2015 na Saúde Animal Clínica Veterinária em Pitanga, PR, uma cadela de aproximadamente dois anos, Daschund com sete kg, castrada, com histórico de ter engolido um objeto de chumbo usado nas redes e linhas de pesca de aproximadamente $2,5 \mathrm{~cm}$ de diâmetro há 20 dias. A mesma não apresentou qualquer sintomatologia clínica ou comportamental durante este período, como relatado também por Parra (2012) e Glaser Filho (2008). Na ocasião do atendimento o proprietário relatou anorexia e vômito há dois dias. A paciente encontrava-se hidratada, com mucosas normocoradas, frequências cardíaca e respiratória normais, sem sensibilidade abdominal, temperatura de 38,5graus Celsius. Foi encaminhado para análise radiográfica onde foi identificada a presença de corpo estranho esferóide radiopaco com aproximadamente $2,5 \mathrm{~cm}$ diâmetro em fundo gástrico. O planejamento terapêutico instituído foi o cirúrgico, sendo realizado gastrostomia para a retirada do corpo estranho (Figura 1). A paciente manteve-se internada na clinica sob fluidoterapia com ringer lactato IV, antibioticoterapia com sulfa + trimetoprim $30 \mathrm{mg} / \mathrm{kg}$ BID IV, antagonista histaminérgico $\mathrm{H} 2$ ranitidina $2 \mathrm{mg} / \mathrm{kg}$ TID IV e analgesia com tramadol $2 \mathrm{mg} / \mathrm{kg}$ BID IV sendo introduzida alimentação pastosa gradativamente após $48 \mathrm{~h}$ do procedimento cirúrgico. A paciente foi encaminhada para a residência com medicação oral e dieta pastosa. Após 10 dias, foi feita a retirada de pontos e a paciente foi acompanhada por mais 30 dias quanto a sinais de intoxicação. Após 180 dias de acompanhamento da paciente não foi observado alterações neurológicas, hematológicas ou gastroentéricas.
Figura 1: Procedimento cirúrgico realizado em cadela da raça Daschund de dois anos para remoção de corpo estranho no estômago. A - Gastrotomia; B- Corpo estranho de chumbo (chumbada) retirado do animal da raça Daschund.

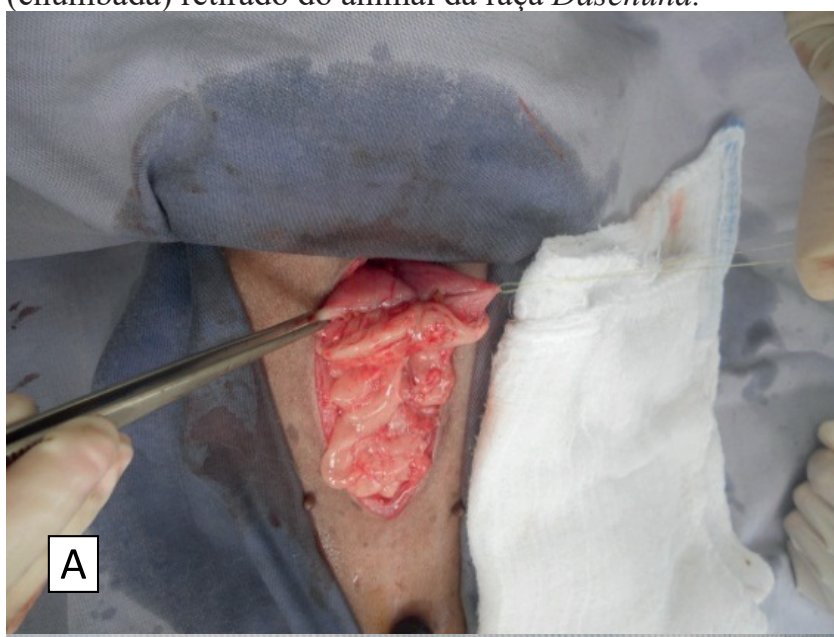

B

\section{Discussão}

Apesar da paciente ter ingerido o corpo estranho há 20 dias, não foi observado sintomatologia gastroentérica durante este período. Segundo Fossum (2005), vômito pode ser intermitente e alguns animais podem continuar a comer e permanecer ativos. Se o corpo estranho estiver no fundo gástrico e não obstruir o piloro, o vômito frequentemente estará ausente.

O vômito (não a regurgitação) é um sinal comum, mas alguns animais demonstram somente anorexia, enquanto outros são assintomáticos (WILLARD, 2010).

Se o objeto for pequeno e apresentar bordas arredondadas, pode-se induzir vômito usando apomorfina em cães ou xilazina em gatos. No entanto, só se deverá tentar isso quando o clinico tiver certeza de que o objeto será expulso sem causar danos. A maior parte dos corpos estranhos pode ser removida facilmente por meio de gastrostomia (FOSSUM, 2005). Devido à cronicidade e tamanho do objeto, optou-se pelo tratamento cirúrgico neste caso (XAVIER, 2013), uma vez que a paciente não apresentava alterações que impossibilitassem tal procedimento, como desidratação, sinais de intoxicação ou outros.

Os achados laboratoriais dependem da gravidade e da duração da obstrução, não podendo ser previstos. Os parâmetros laboratoriais podem permanecer normais ou mostrar 
somente alterações causadas por desidratação (hematócrito, proteína total, nitrogênio ureico sérico e creatinina) (FOSSUM, 2005). No caso relatado não foram observadas alterações séricas em hemograma, ureia, creatinina e ALT (Alanina Amino Transferase) como citado por Fossum (2005), encorajando nossa escolha pelo tratamento cirúrgico.

A paciente se recuperou plenamente após gastrotomia, voltando a se alimentar após $48 \mathrm{~h}$ com alimentação pastosa, uma vez que não apresentou vômitos durante o pós-operatório. Fossum (2005) relata que se o paciente não apresentar emese, deverá ser oferecida uma dieta leve 12 a $24 \mathrm{~h}$ após a cirurgia com prognostico bom se o estômago não tiver sido perfurado e o corpo estranho for removido. No caso relatado por Oliveira (2016), semelhantemente, a paciente recuperou-se do procedimento cirúrgico sem complicações e não apresentou sinais clínicos de intoxicação púmblica pelo período acompanhado de 180 dias.

O exame laboratorial mais indicado para o diagnóstico de intoxicação por chumbo é a detecção desse elemento químico nas fezes, na urina, no leite, e principalmente no sangue, segundo Hueza (2005).

Outro método diagnóstico empregado é a avaliação da concentração do ácido ${ }^{\delta}$ aminovulemico na urina (JERICÓ, 2015), porém os mesmos não foram avaliados uma vez que o proprietário não autorizou, já que a mesma não apresentava sintomatologia neurológica ou gástrica de intoxicação por chumbo. Apesar da via oral ser a principal via de exposição de chumbo para animais, a absorção depende da solubilidade do sal de chumbo ingerido. Dessa forma, o chumbo metálico e sua forma sulfídica são pouco absorvidas, enquanto as formas de sais de acetato, de fosfato e de óxido de carbono são mais facilmente absorvidos pelo trato gastrintestinal (JERICÓ, 2015).

Contrariamente ao que foi observado por Palumbo (2010), onde relatam sinais neurológicos em um cão que ingeriu objetos metálicos há um tempo indeterminado, diagnosticando a presença dos mesmos em necropsia e confirmada a intoxicação pumblica com analises toxicológicas em fígado e rins, não foi, após 180 dias de acompanhamento, observado sinais de intoxicação por chumbo, mantendo-a sob observação domiciliar para possíveis complicações.

Cordeiro e Lima Filho (1995) relatam que o chumbo é um elemento estranho ao metabolismo animal em qualquer quantidade e que é considerado neurotoxina em concentrações criticas, interferindo em diversas vias metabólicas. Porém, no caso relatado, a falta de sintomatologia, mesmo sem exames complementares, nos permite concluir que apesar da presença de corpo estranho de chumbo no estômago canino por aproximadamente 20 dias, não causou intoxicação devido à baixa absorção do metal devido a sua forma insolúvel.

Assim como Oliveira (2016) relatou, a paciente foi submetida a gastrotomia sem complicações e não apresentou sinais de intoxicação por chumbo por seis meses de acompanhamento clínico

\section{Conclusão}

Após a visualização de ingestão de corpo estranho de chumbo, e confirmação com exames complementares, no caso, radiografia simples, o diagnóstico de corpo estranho gástrico foi concluído mesmo com ausência de sinais clíni- cos típicos de corpo estranho em cães.

O protocolo terapêutico cirúrgico foi instituído para a retirada do mesmo com sucesso, sendo que a paciente voltou a se alimentar após $48 \mathrm{~h}$ do procedimento e teve alta clínica após 10 dias de pós-operatório.

Apesar da falta de confirmação com dosagens séricas de chumbo, concluiu-se que a paciente não teve intoxicação por chumbo uma vez que não apresentou sintomatologia durante a presença do corpo estranho bem como no pós operatório recente, devido a forma metálica do corpo estranho.

\section{Referências}

CORDEIRO, R.; LIMA-FILHO, E. C. A inadequação dos valores dos limites de tolerância biológica para prevenção da intoxicação profissional pelo chumbo no Brasil.

Caderno de Saúde Pública, v. 11, n. 2, p. 177-186, 1995.

ETTINGER, S. J. ; FELDMAN, E. C. Tratado de Medicina Interna Veterinária. 4. ed. v. 2. São Paulo: Manole. 1997. p. 1607

FOSSUM, T. W. Cirurgia do sistema digestório. In: FOSSUM, T.W. Cirurgia de pequenos animais. 2. ed. São Paulo, Roca, 2005, p.339-354.

\section{GLASER FILHO, R. A. Corpo estranho gastrintestinal} linear em cão - relato de caso. Curitiba, 2008. Dissertação (curso de pós graduação “ lato sensu” em clínica cirúrgica de pequenos animais). Instituto Qualitas, Curitiba, 2008.

HUEZA, I. M. et al.Toxicologia do chumbo, mercúrio, arsênio e de outros metais. In: SPINOSA, H. S.; GORNIAK, L. S.; PALERMO, J. P. Toxicologia aplicada à Medicina Veterinária, São Paulo, Manole, 2008.

JERICÓ, M. M. Tratado de medicina interna de cães e gatos. Rio de Janeiro, Roca, 2015.

MACINTIRE,D. K. et al. Emergência e cuidados intensivos em pequenos animais. São Paulo, Manole, 2007, p. 201-209.

OLIVEIRA, F. L. D.; BASTOS, R. C. Ingestão de chumbo de pesca em cão - relato de caso. Clínica Veterinária, v. 21, n. 121, p. 42-49, 2016.

PALUMBO, M. I. P. et al. Lead poisoning in dog - case report. Archives of Veterinary Science, v. 15, n. 3, p. 157162, 2010.

PARRA, T. C. et al. Ingestão de corpo estranho em cães relato de caso. Revista Científica Eletrônica de Medicina Veterinária, v. 9, n. 18, 2012.

RUPPENTHAL, J. E. Toxicologia. Universidade Federal de Santa Maria, Colégio Técnico Industrial de Santa Maria: Santa Maria, 2013, p. 38.

STURGESS, C. P. Doenças do trato alimentar. In: DUNN, J. K. Tratado de medicina de pequenos animais. São 
Paulo, Roca, 2001, p. 367-407.

XAVIER, M. R. B. et al. Corpo estranho linear em cão - relato de caso. In: 13., Jornada de Ensino, Pesquisa e Extensão da UFRPE, Recife. Anais... Recife: UFRPE. Recife, 2013.

WILLARD, M. D. Distúrbios do sistema digestório. In: NELSON, R.W.; COUTO, C. G. Medicina interna de pequenos animais, 4. ed. Rio de Janeiro, Elsevier, 2010, p.351-484.

Recebido em: 23.04.2016

Aceito em: 06.09.2017 